\title{
Perchlorate Selectivity of Anion Exchange Resins as Evaluated Using Ion-Selective Electrodes
}

\author{
Kenji Yamamoto, Shin'ya Mitsuda, Naomi Ohtake, Natsuki Murashige, Satoshi Ohmuro, and \\ Akio YuCHI ${ }^{\dagger}$
}

Graduate School of Engineering, Nagoya Institute of Technology, Gokiso, Showa, Nagoya 466-8555, Japan

\begin{abstract}
The selectivity coefficients reported for perchlorate of the high selectivity on anion exchange resins (AXRs) have not been consistent with one another. Possible errors by the unique use of four parameters (concentrations of two anions in two phases) were experimentally verified. The concentrations of perchlorate buffered at low levels $\left(10^{-6}-10^{-4} \mathrm{~mol} \mathrm{~L}^{-1}\right)$ by two forms of AXRs were successfully determined by potentiometry with a perchlorate ion-selective electrode. This gave reasonable coefficients. The coefficients for perchlorate on several AXRs were independent of the relative exchange (RE), in contrast to the previous reports. On the other hand, the coefficients for fluoride of the low selectivity that were examined for comparison decreased with an increase in RE, and the dependency was more remarkable for the resins of large exchange capacity.
\end{abstract}

Keywords Anion exchange resin, perchlorate, selectivity coefficient, ion-selective electrode

(Received July 25, 2016; Accepted September 1, 2016; Published February 10, 2017)

\section{Introduction}

Perchlorate as a contaminant in groundwater and surface water has attracted attention because of its adverse effects such as inhibition of iodide uptake and endocrine-disruption. ${ }^{1,2}$ Ionexchange resin technology is believed to be promising for removal of perchlorates in water. From the practical viewpoint, new resins and technologies have been developed for the purpose of achieving rapid exchange, enhancing the sorption capacity, allowing for desorption of perchlorate and reuse of the resin, and decomposing perchlorate in the resin phase..$^{3-9}$ Fundamental information, however, has been limited. For example, only one of these papers described the most important parameter of the selectivity coefficient; $\log K_{\mathrm{Cl}}{ }^{\mathrm{ClO} 4}: 2.72$ for QPEI-4 (hyperbranched polyethyleneimine-type resin), 2.78 for A-530E (styrene divinylbenzene-type resin). ${ }^{9}$

The coefficients of varying anions on the conventional resins were independently studied by several groups in the $1950 \mathrm{~s}^{10-13}$ and later. ${ }^{14,15}$ These values were in reasonable agreement with each other except for perchlorate, for which extremely different values were reported: for example, $\log K_{\mathrm{Cl}}{ }^{\mathrm{ClO} 4}: 2.18$ and 1.5 for type I (with trimethylaminomethyl group, cross-linking of $8 \%$ ); ${ }^{12,15} 1.4$ for type II (with 2-hydroxyethyldimethylaminomethyl group). ${ }^{11}$ Even a variation in selectivity coefficient according to the relative exchange was suggested and discussed. ${ }^{11,14-17}$ Under such circumstances, a recent paper described the coefficient only at the molar fraction of $\mathrm{ClO}_{4}{ }^{-}$of $10^{-4}$ level in the resin phase. ${ }^{18}$ The modern handbooks do not include the coefficient for perchlorate. ${ }^{19}$

In this study, we first demonstrated the difficulty in

$\dagger$ To whom correspondence should be addressed.

E-mail: yuchi.akio@nitech.ac.jp determining the coefficient for perchlorate, which leads to inconsistency of literature data, from the experimental points of view. We have successfully reevaluated the selectivity coefficients of perchlorate on the resins of different exchange capacities, cross-linking degrees, and basicities by potentiometry with an ion-selective electrode (ISE). The coefficients of other typical anions of lower affinities (fluoride, chloride, and nitrate) were also determined by ion chromatography (IC), and the dependency of the coefficient on the composition of the resin phase has been discussed.

\section{Experimental}

\section{Reagents and chemicals}

Four strongly basic anion exchange resins (SBAs) and four weakly basic anion exchange resins (WBAs) were evaluated. Among them, three SBAs and one WBA were commercially available (Dowex $1 \times 2$, Dowex $1 \times 8$, Dowex $2 \times 8$, and Dowex WBA abbreviated as I- $3 \times 2$, I- $3 \times 8$, II- $2 \times 8$, and W-4, respectively; the first digit denotes an approximate exchange capacity and the second digit, if applicable, denotes the cross-linking degree by divinybenzene; macroporous), while the gel-type resin of a low exchange capacity with trimethylaminomethyl group (I-1×2) and those with dimethylamino group (W-1, 2, 3) were derived from the Merrifield resins (TCI, Cl contents $/ \mathrm{mmol} \mathrm{g}^{-1}$, crosslinking: $0.9,2 \% ; 1.9,2 \% ; 2.9,1 \%$ ) as described previously. ${ }^{20,21}$ Introduction of the ammonium or amino group was confirmed by the decrease in IR absorption around $1265 \mathrm{~cm}^{-1}$ due to H-C-Cl stretching. ${ }^{22}$ The IR spectra showed that only W-4 among WBAs had strong broad absorption centered at $3450 \mathrm{~cm}^{-1}$ with a half-height width of $300 \mathrm{~cm}^{-1}$; this suggests the presence of some hydrophilic group. Each of the SBAs was treated with a $\mathrm{NaCl}$ or $\mathrm{NaBr}$ solution by a flow system to be 
Table 1 Properties of SBAs and WBAs as free base

\begin{tabular}{|c|c|c|c|c|}
\hline SBA, form & Type & Origin & $\begin{array}{l}\text { Exchange } \\
\text { capacity/ } \\
\text { mmol g-1 }\end{array}$ & $n^{\mathrm{b}}$ \\
\hline $\mathrm{I}-1 \times 2, \mathrm{Br}^{-}$ & Gel & a & $0.77 \pm 0.03$ & 10 \\
\hline $\mathrm{I}-3 \times 2, \mathrm{Br}^{-}$ & Porous & Dowex $1 \times 2$ & $3.17 \pm 0.02$ & 9 \\
\hline $\mathrm{I}-3 \times 8, \mathrm{Br}^{-}$ & Porous & Dowex $1 \times 8$ & $2.76 \pm 0.02$ & 9 \\
\hline $\mathrm{II}-2 \times 8, \mathrm{Br}^{-}$ & Porous & Dowex $2 \times 8$ & $2.18 \pm 0.02$ & 4 \\
\hline $\mathrm{II}-2 \times 8, \mathrm{Cl}^{-}$ & Porous & Dowex $2 \times 8$ & 2.58 & 1 \\
\hline WBA & Type & Origin & $\begin{array}{l}\text { Nitrogen } \\
\text { content/ } \\
\text { mmol g- }^{-1}\end{array}$ & $\begin{array}{c}\text { Water } \\
\text { content, } \\
\%\end{array}$ \\
\hline $\mathrm{W}-1$ & Gel & $\mathrm{a}$ & 0.84 & 0.1 \\
\hline $\mathrm{W}-2$ & Gel & $\mathrm{a}$ & 2.02 & 0.2 \\
\hline $\mathrm{W}-3$ & Gel & $\mathrm{a}$ & 2.77 & 0.4 \\
\hline W-4 & Porous & Dowex WBA & 4.19 & 2.9 \\
\hline
\end{tabular}

a. Derived from Merrified resin.

b. Number of data.

the $\mathrm{Cl}$-form or $\mathrm{Br}$-form, while all the WBAs were thoroughly washed with water. The resins were stored in a glove box maintained at $25^{\circ} \mathrm{C}$ and at relative humidity of $50 \%$.

SBAs of 10 to $30 \mathrm{mg}$ were accurately weighed and were equilibrated with 6 to $10 \mathrm{mmol} \mathrm{L}^{-1} \mathrm{NaClO}_{4}$ solutions. The $\mathrm{Cl}^{-}$ or $\mathrm{Br}^{-}$content in the supernatant was determined. The accurately calculated exchange capacity of SBA is summarized in Table 1. The appreciable difference in exchange capacity between $\mathrm{Br}$-form and $\mathrm{Cl}$-form for II- $2 \times 8$ is attributable to the difference in molecular weight between $\mathrm{Br}^{-}$and $\mathrm{Cl}^{-}$and the difference between their hydration numbers as published previously. ${ }^{21}$

The precise chemical amounts of the free base amine in WBAs determined by elemental analysis of nitrogen and the water content determined by Karl-Fischer coulometry in conjunction with water vaporization (Mitsubishi Chemical, CA-100 and VA-100) are summarized in Table 1. The water content of WBA was generally lower than that of SBA. ${ }^{21}$ The higher water content of W-4 than the other WBAs supported the introduction of some hydrophilic group suggested from the IR spectrum.

\section{General consideration on ion-exchange equilibrium analysis}

In the equilibration of $\mathrm{X}^{-}$-form resin $\left(m \mathrm{~g}\right.$; $\mathrm{TA}_{\mathrm{X}} / \mathrm{mmol}$ : total amount of $\left.\mathrm{X}^{-}\right)$with a solution containing $\mathrm{A}^{-}\left(q \mathrm{~mL} ; \mathrm{TA}_{\mathrm{A}} / \mathrm{mmol}\right.$ : total amount of $\left.\mathrm{A}^{-}\right)$, the selectivity coefficient of $\mathrm{A}^{-}$relative to $\mathrm{X}^{-}$is expressed by:

$$
K_{\mathrm{X}^{\mathrm{A}}}=\left(\left[-\mathrm{R}^{+}, \mathrm{A}^{-}\right]\left[\mathrm{X}^{-}\right]\right) /\left(\left[-\mathrm{R}^{+}, \mathrm{X}^{-}\right]\left[\mathrm{A}^{-}\right]\right)
$$

where $\left[\mathrm{X}^{-}\right]$and $\left[\mathrm{A}^{-}\right]$denote the concentrations of $\mathrm{X}^{-}$and $\mathrm{A}^{-}$in the aqueous phase expressed by $\mathrm{mol} \mathrm{L}^{-1}$ and are determinable by analysis of the supernatant, while $\left[-\mathrm{R}^{+}, \mathrm{X}^{-}\right]$and $\left[-\mathrm{R}^{+}, \mathrm{A}^{-}\right]$ denote those in the resin phase expressed by mol kg-1 and are available from analysis of the eluent after separation and complete elution of anions from the resin phase.

The mass balances of $\mathrm{X}^{-}$and $\mathrm{A}^{-}$are respectively expressed as Eqs. (2) and (3):

$$
\begin{aligned}
& \mathrm{TA}_{\mathrm{X}}=\left[-\mathrm{R}^{+}, \mathrm{X}^{-}\right] \times m+\left[\mathrm{X}^{-}\right] \times q \\
& \mathrm{TA}_{\mathrm{A}}=\left[-\mathrm{R}^{+}, \mathrm{A}^{-}\right] \times m+\left[\mathrm{A}^{-}\right] \times q
\end{aligned}
$$

From the macroscopic electroneutrality, Eq. (4) holds:

$$
\left[-\mathrm{R}^{+}, \mathrm{A}^{-}\right] \times m=\left[\mathrm{X}^{-}\right] \times q
$$

Since the four parameters, $\left[\mathrm{X}^{-}\right],\left[\mathrm{A}^{-}\right],\left[-\mathrm{R}^{+}, \mathrm{X}^{-}\right]$and $\left[-\mathrm{R}^{+}, \mathrm{A}^{-}\right]$are related to each other by Eqs. (2) - (4), the coefficient $K_{\mathrm{X}^{\mathrm{A}}}$ may be calculated from only one of them by Eqs. (5) - (8):

$$
\begin{aligned}
& K_{\mathrm{X}^{\mathrm{A}}}\left(\left[\mathrm{X}^{-}\right]\right)=\left(\left[\mathrm{X}^{-}\right] \times q\right)^{2} /\left(\left(\mathrm{TA}_{\mathrm{X}}-\left[\mathrm{X}^{-}\right] \times q\right)\left(\mathrm{TA}_{\mathrm{A}}-\left[\mathrm{X}^{-}\right] \times q\right)\right)(5) \\
& K_{\mathrm{X}} \mathrm{A}\left(\left[\mathrm{A}^{-}\right]\right)=\left(\mathrm{TA}_{\mathrm{A}}-\left[\mathrm{A}^{-}\right] \times q\right)^{2} / \\
& \left(\left(\mathrm{TA}_{\mathrm{X}}-\mathrm{TA}_{\mathrm{A}}+\left[\mathrm{A}^{-}\right] \times q\right)\left(\left[\mathrm{A}^{-}\right] \times q\right)\right) \\
& K_{\mathrm{X}}^{\mathrm{A}}\left(\left[-\mathrm{R}^{+}, \mathrm{X}^{-}\right]\right)=\left(\mathrm{TA}_{\mathrm{X}}-\left[-\mathrm{R}^{+}, \mathrm{X}^{-}\right] \times m\right)^{2} / \\
& \left(\left[-\mathrm{R}^{+}, \mathrm{X}^{-}\right] \times m \times\left(\mathrm{TA}_{\mathrm{A}}-\mathrm{TA}_{\mathrm{X}}+\left[-\mathrm{R}^{+}, \mathrm{X}^{-}\right] \times m\right)\right) \\
& K_{\mathrm{X}} \mathrm{A}^{\mathrm{A}}\left(\left[-\mathrm{R}^{+}, \mathrm{A}^{-}\right]\right)=\left(\left[-\mathrm{R}^{+}, \mathrm{A}^{-}\right] \times m\right)^{2} / \\
& \left(\left(\mathrm{TA}_{\mathrm{X}}-\left[-\mathrm{R}^{+}, \mathrm{A}^{-}\right] \times m\right)\left(\mathrm{TA}_{\mathrm{A}}-\left[-\mathrm{R}^{+}, \mathrm{A}^{-}\right] \times m\right)\right)
\end{aligned}
$$

The relative exchange (RE) of $\mathrm{X}^{-}$on the resin by $\mathrm{A}^{-}$is also calculable from one of four parameters by Eqs. (9) - (12):

$$
\begin{aligned}
& \operatorname{RE}\left(\left[\mathrm{X}^{-}\right]\right)=\left(\left[\mathrm{X}^{-}\right] \times q\right) / \mathrm{TA}_{\mathrm{X}} \\
& \operatorname{RE}\left(\left[\mathrm{A}^{-}\right]\right)=\left(\mathrm{TA}_{\mathrm{A}}-\left[\mathrm{A}^{-}\right] \times q\right) / \mathrm{TA}_{\mathrm{X}} \\
& \operatorname{RE}\left(\left[-\mathrm{R}^{+}, \mathrm{X}^{-}\right]\right)=\left(\mathrm{TA}_{\mathrm{X}}-\left[-\mathrm{R}^{+}, \mathrm{A}^{-}\right] \times m\right) / \mathrm{TA}_{\mathrm{X}} \\
& \operatorname{RE}\left(\left[-\mathrm{R}^{+}, \mathrm{A}^{-}\right]\right)=\left(\left[-\mathrm{R}^{+}, \mathrm{A}^{-}\right] \times m\right) / \mathrm{TA}_{\mathrm{X}}
\end{aligned}
$$

Reliable analysis needs to observe the RE in the range of 0.1 to 0.9 , which corresponds to the range of 3 to 4 in $\log \left[\mathrm{A}^{-}\right]$. Suitable analytical method is required, depending on the property and the concentration of the relevant anion.

\section{Procedure}

SBAs of 10 to $100 \mathrm{mg}$ (Cl-form of II- $2 \times 8$ for exchange by $\mathrm{NO}_{3}{ }^{-}$and $\mathrm{Br}$; $\mathrm{Br}$-forms for the others) were shaken with a series of sodium salt solutions of relevant anions $\left(25 \mathrm{~mL}\right.$ of $10^{-3.5}$ $10^{-1.0} \mathrm{~mol} \mathrm{~L}^{-1}$; chemical amount ratio of anion to ion-exchange group $=0.3-100)$. After equilibration, the resins were filtered off and were shaken with $\mathrm{NaClO}_{4}$ solutions to elute anions in the resin phase.

In the case of WBAs (-N), coadsorption of strong acids (HA: $\mathrm{HClO}_{4}, \mathrm{HNO}_{3}, \mathrm{HBr}$ or $\mathrm{HCl}$; $\mathrm{HF}$ was not included because of experimental difficulty) given by Eq. (13) was first evaluated.

$$
-\mathrm{N}+\mathrm{H}^{+}+\mathrm{A}^{-}=\left(-\mathrm{NH}^{+}, \mathrm{A}^{-}\right)
$$

Based on the results, 10 to $100 \mathrm{mg}$ neutral base resins were shaken with a series of mixtures of two acids with the total concentration kept at $10^{-2} \mathrm{~mol} \mathrm{~L}^{-1}$. In the presence of proton at $10^{-2} \mathrm{~mol} \mathrm{~L}^{-1}$, the free bases of WBAs except W-1 became wet and were protonated to have ion exchange ability. After equilibration, the resins were filtered off and were shaken with $\mathrm{NaOH}$ solutions to elute anions.

Both the supernatants and the eluents were subjected to IC with conductometric detection. The condition (eluent of $8 \mathrm{mmol} \mathrm{L}^{-1} p$-hydroxybenzoic acid and $2.8 \mathrm{mmol} \mathrm{L}^{-1}$ Bis-Tris, $\mathrm{pH}$ 3.6) was suited for the determination of $\mathrm{F}^{-}, \mathrm{Cl}^{-}, \mathrm{Br}^{-}$and $\mathrm{NO}_{3}{ }^{-}$but not for that of $\mathrm{ClO}_{4}^{-}$because of serious broadening of the peak.

Perchlorate ISE was prepared as described previously using tri(dodecyl)methylammonium chloride and was conditioned in a $10^{-2} \mathrm{~mol} \mathrm{~L}^{-1} \mathrm{NaClO}_{4}$ solution before use. ${ }^{23}$ The potential of the following cell kept at $25^{\circ} \mathrm{C}$ was used for the potentiometric determination of $\mathrm{ClO}_{4}^{-}$: 


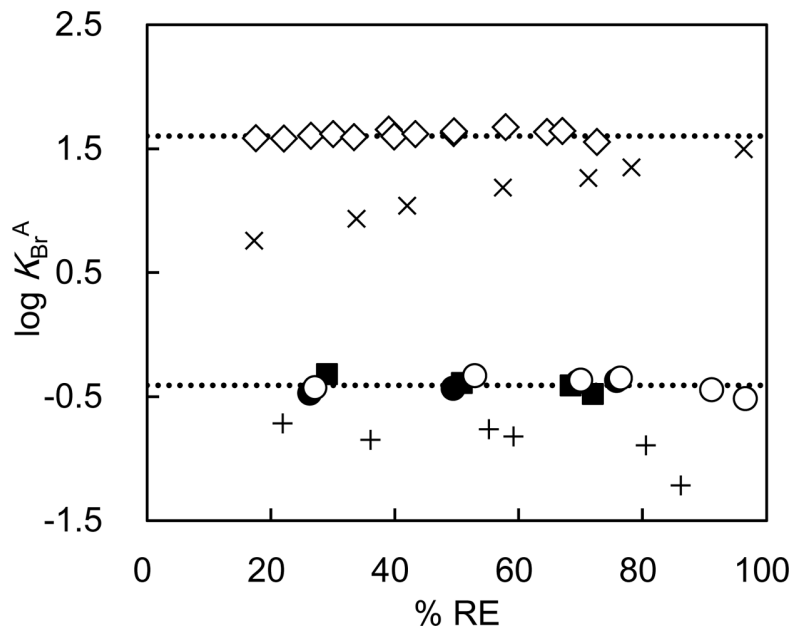

Fig. 1 RE dependency of $\log K_{\mathrm{Br}}{ }^{\mathrm{A}}$ calculated with different parameters on I-3×8. $\bullet, \mathbf{\square}, \bigcirc,+$ : Logarithmic value of $K_{\mathrm{Br}}{ }^{\mathrm{CNO}}\left(\left[\mathrm{Br}^{-}\right]\right)$, $K_{\mathrm{Br}}{ }^{\mathrm{CNO}}\left(\left[\mathrm{CNO}^{-}\right], K_{\mathrm{Br}}{ }^{\mathrm{CNO}}\left(\left[-\mathrm{R}^{+}, \mathrm{Br}-\right]\right)\right.$, and $K_{\mathrm{Br}}{ }^{\mathrm{CNO}}\left(\left[-\mathrm{R}^{+}, \mathrm{CNO}^{-}\right]\right)$determined by IC. $\diamond, \times$ : Logarithmic value of $K_{\mathrm{Br}}{ }^{\mathrm{ClO}}\left(\left[\mathrm{ClO}_{4}^{-}\right]\right)$by ISE and $K_{\mathrm{Br}}{ }^{\mathrm{ClO} 4}([\mathrm{Br}-])$ by IC. Two horizontal lines indicate the average logarithmic values of $K_{\mathrm{Br}}{ }^{\mathrm{CNO}}$ and $K_{\mathrm{Br}}{ }^{\mathrm{ClO}}$ from the bottom.

$\mathrm{Ag} / \mathrm{AgCl} \mid \mathrm{NaCl}$ (satd.) || sample solution | membrane $10^{-2} \mathrm{~mol} \mathrm{~L}^{-1} \mathrm{NaCl}$ and $\mathrm{NaClO}_{4}$, phosphate buffer (pH 6.8) $\mathrm{Ag} / \mathrm{AgCl}$

A saturated $\mathrm{NaCl}$ solution instead of $\mathrm{KCl}$ was used for the salt bridge, in order to avoid possible precipitation of $\mathrm{KClO}_{4}$. The potentiometric interference by $\mathrm{Br}^{-}$or $\mathrm{Cl}^{-}$was taken into consideration as appropriate.

The selectivity coefficients and relative exchanges were calculated according to Eqs. (5) - (12). Taking into consideration a change in activity coefficient in the aqueous phase, the number of decimal places of selectivity coefficients was limited to unity. The coefficients of $K_{\mathrm{Br}}{ }^{\mathrm{Cl}}$ and $K_{\mathrm{Br}}{ }^{\mathrm{NO} 3}$ for II- $2 \times 8$ were calculated with $K_{\mathrm{Cl}}^{\mathrm{Br}}$ and $K_{\mathrm{Cl}}^{\mathrm{NO} 3}$ based on the additivity. All the numerical data on ion-exchange are given in Tables S1 - S23 (Supporting Information).

\section{Results and Discussion}

\section{Evaluation of selectivity coefficients with four parameters}

Preliminarily, four parameters $\left[\mathrm{X}^{-}\right],\left[\mathrm{A}^{-}\right],\left[-\mathrm{R}^{+}, \mathrm{X}^{-}\right]$and $\left[-\mathrm{R}^{+}, \mathrm{A}^{-}\right]$ involved in the exchange of the $\mathrm{Br}$-form of $\mathrm{I}-3 \times 8$ by $\mathrm{CNO}^{-}\left(\mathrm{X}^{-}\right.$: $\left.\mathrm{Br}^{-} ; \mathrm{A}^{-}: \mathrm{CNO}^{-}\right)$were determined by a versatile apparatus of IC, and all the four types of $K_{\mathrm{Br}}{ }^{\mathrm{CNO}}$ and $\mathrm{RE}$ were calculated with a view to enhancing the reliability of and focusing on the difficulty in the evaluation. As shown in Fig. 1, the coefficients were in good agreement with one another, except $K_{\mathrm{Br}}{ }^{\mathrm{CNO}}\left(\left[-\mathrm{R}^{+}, \mathrm{CNO}^{-}\right]\right)$ that was plotted against $\mathrm{RE}\left(\left[-\mathrm{R}^{+}, \mathrm{CNO}^{-}\right]\right)$. The deviation of $K_{\mathrm{Br}}{ }^{\mathrm{CNO}}\left(\left[-\mathrm{R}^{+}, \mathrm{CNO}^{-}\right]\right)$was attributed to the unique partial decomposition of $\mathrm{CNO}^{-}$in the elution step as verified by the appearance of other peaks in ion chromatography.

At the high $\mathrm{RE}(>0.8)$ where $\left[-\mathrm{R}^{+}, \mathrm{Br}^{-}\right]$became small, $K_{\mathrm{Br}}{ }^{\mathrm{CNO}}\left(\left[\mathrm{Br}^{-}\right]\right)$and $K_{\mathrm{Br}}{ }^{\mathrm{CNO}}\left(\left[\mathrm{CNO}^{-}\right]\right)$(omitted) could not be evaluated properly, because of unreliable estimates of $\left[-\mathrm{R}^{+}, \mathrm{Br}^{-}\right]$ from $\left[\mathrm{Br}^{-}\right]$and $\left[\mathrm{CNO}^{-}\right]$, respectively. Only direct measurement of $\left[-\mathrm{R}^{+}, \mathrm{Br}-\right]$ after elution gave reasonable results at the high $\mathrm{RE}$. In summary, any parameters can be used to evaluate the coefficient for anions of moderate selectivity at $\mathrm{RE}=0.2-0.8$.
Selectivity coefficients of $\mathrm{ClO}_{4}^{-}$with use of ion selective electrode

The supernatant in exchange of the $\mathrm{Br}$-form of $\mathrm{I}-3 \times 8$ by $\mathrm{ClO}_{4}^{-}$ $\left(\mathrm{X}^{-}: \mathrm{Br}^{-} ; \mathrm{A}^{-}: \mathrm{ClO}_{4}^{-}\right)$was subjected to IC for the purpose of determining $\left[\mathrm{Br}^{-}\right]$. Unless a special column and eluent were adopted, ${ }^{9} \mathrm{ClO}_{4}^{-}$could not be determined by IC. Thus, neither $K_{\mathrm{Br}}{ }^{\mathrm{ClO} 4}\left(\left[\mathrm{ClO}_{4}^{-}\right]\right)$by Eq. (6) nor $K_{\mathrm{Br}^{\mathrm{ClO}} 4}\left(\left[-\mathrm{R}^{+}, \mathrm{ClO}_{4}^{-}\right]\right)$by Eq. (8) was obtained in this study. The $K_{\mathrm{Br}}{ }^{\mathrm{ClO} 4}\left(\left[\mathrm{Br}^{-}\right]\right)$plotted in Fig. 1 shows an increase with an increase in RE, but this is not reliable since the anion of the high selectivity, $\mathrm{ClO}_{4}^{-}$, almost quantitatively exchanges $\mathrm{Br}^{-}$in the resin. For example, in the case of exchange of $10 \mathrm{mg}$ of $\mathrm{I}-3 \times 8$ by $\mathrm{ClO}_{4}^{-}$at 2.00 and $4.00 \times 10^{-4} \mathrm{~mol} \mathrm{~L}^{-1}$, the bromide concentration determined was 1.93 and $3.78 \times 10^{-4} \mathrm{~mol} \mathrm{~L}^{-1}$, respectively. $\left[\mathrm{ClO}_{4}^{-}\right]$calculated from the difference, 0.07 and $0.22 \times 10^{-4} \mathrm{~mol} \mathrm{~L}^{-1}$, suffered from a large positive error. Thus, $K_{\mathrm{Br}}{ }^{\mathrm{ClO} 4}\left(\left[\mathrm{Br}^{-}\right]\right)$, if available, systematically suffered from a negative error. This trend is more remarkable at the low $\mathrm{RE}$ on low loading.

Under such conditions, $\left[\mathrm{ClO}_{4}^{-}\right]$is, in a sense, buffered at a low concentration level $\left(10^{-6}-10^{-5} \mathrm{~mol} \mathrm{~L}^{-1}\right.$ level) by a pair of $\left[-\mathrm{R}^{+}, \mathrm{ClO}_{4}^{-}\right]$and $\left[-\mathrm{R}^{+}, \mathrm{Br}^{-}\right]$, and separation of the supernatant from the resin is prone to suffer from a large error in quantitation as in the case of $\mathrm{pH}$ measurement of a neutral solution in the absence of a $\mathrm{pH}$ buffer. Although a special ion chromatographic system with a $\mathrm{ClO}_{4}^{-}$detection limit of $2 \mathrm{ppb}=2 \times 10^{-8} \mathrm{~mol} \mathrm{~kg}^{-1}$ was used in the recent paper, ${ }^{9}$ in situ determination of $\left[\mathrm{ClO}_{4}^{-}\right]$in the presence of both types of resins is preferable. Potentiometry of perchlorate with ISE responding to the logarithmic concentration is suitable in these respects just as potentiometry of proton with a glass electrode is suited for $\mathrm{pH}$ determination of buffered solutions.

The $K_{\mathrm{Br}}{ }^{\mathrm{ClO} 4}\left(\left[\mathrm{ClO}_{4}^{-}\right]\right)$using $\left[\mathrm{ClO}_{4}^{-}\right]$determined by ISE is also plotted in Fig. 1. The $K_{\mathrm{Br}}{ }^{\mathrm{ClO} 4}\left(\left[\mathrm{ClO}_{4}^{-}\right]\right)$value was independent of $\mathrm{RE}$ in contrast to the previous paper, ${ }^{11}$ and was close to the $K_{\mathrm{Br}}{ }^{\mathrm{ClO} 4}\left(\left[\mathrm{Br}^{-}\right]\right)$value using $\left[\mathrm{Br}^{-}\right]$by IC at the high RE. This is because the error in $K_{\mathrm{Br}}{ }^{\mathrm{ClO} 4}\left(\left[\mathrm{Br}^{-}\right]\right)$described above is less at the high RE. These results are consistent with each other, so that both the inconsistency and the RE dependency of $K_{\mathrm{X}}^{\mathrm{ClO} 4}$ in the previous work are attributed to the inappropriate anion determination in the supernatant. The $K_{\mathrm{Cl}}{ }^{\mathrm{ClO} 4}$ value of $10^{2.18}$ calculated from the difference between $K_{\mathrm{Br}}{ }^{\mathrm{ClO} 4}$ and $K_{\mathrm{Br}}{ }^{\mathrm{Cl}}$ agreed well with that determined by radiometry. ${ }^{12}$ Potentiometry with ISE is effective and is generally applicable to evaluation of $K_{\mathrm{X}}{ }^{\mathrm{A}}$ for the anions $\mathrm{A}^{-}$of the high selectivity.

\section{Selectivity coefficients of fluoride}

The RE dependencies of the selectivity of four anions on four SBAs are shown in Fig. 2. The coefficients of anions except $\mathrm{F}^{-}$were independent of $\mathrm{RE}$ on any resins. The $\log K_{\mathrm{Br}}{ }^{\mathrm{F}}$ values on $\mathrm{I}-1 \times 2, \mathrm{I}-3 \times 8$ and $\mathrm{I}-3 \times 2$, on the other hand, decreased with an increase in RE from 0 to $100 \%$ by $0.30,0.34$, and 0.43 , respectively (Figs. 2a, 2b, 2c). Fluoride is extremely hydrophilic and is appreciably hydrated even in the resin phase. ${ }^{21}$ The enhanced swelling of the resin at the high $\mathrm{RE}$ by $\mathrm{F}^{-}$is resisted by cross-linking to decrease the $\mathrm{F}^{-}$selectivity. Such a decrease was more remarkable for the resin of the large exchange capacity. A similar decrease was observed for the other hydrophilic anions of carboxylates. ${ }^{24}$

The resin of II- $2 \times 8$ has a hydroxyethyl group, which is likely to serve as a hydrogen-bond donor and interact with $\mathrm{F}^{-}$. The hydration number of $\mathrm{F}^{-}$on II- $2 \times 8$ (4.8) determined as described previously was actually smaller than that on $\mathrm{I}-3 \times 8$ (5.6) by around unity. ${ }^{21}$ As a result, swelling was relieved and the selectivity was kept substantially constant with an increase in RE on II- $2 \times 8$ (Fig. $2 d$ ). 
Coadsorption of acids to and selectivity coefficients on WBAs

The stoichiometric amounts of $\mathrm{H}^{+}$and $\mathrm{A}^{-}$(equal to the chemical amount of the dimethylamino group) were coadsorbed to W-4 at a total acid concentration of greater than $10^{-2} \mathrm{~mol} \mathrm{~L}^{-1}$, while no coadsorption was observed for W-1 because of low wettability. In the case of $\mathrm{W}-2$ and $\mathrm{W}-3$, stoichiometric coadsorption was observed only for $\mathrm{HNO}_{3}, \mathrm{HBr}$, and $\mathrm{HCl}$ after a long equilibration time of around one week, but $\mathrm{HClO}_{4}$ was coadsorbed only up to several tens of percent at the maximum.

Based on these findings, the selectivity coefficients were evaluated for the combination of the acids of quantitative coadsorption as described in the experimental section. The selectivity coefficients were also independent of RE (Tables S17 - 23, Supporting Information).

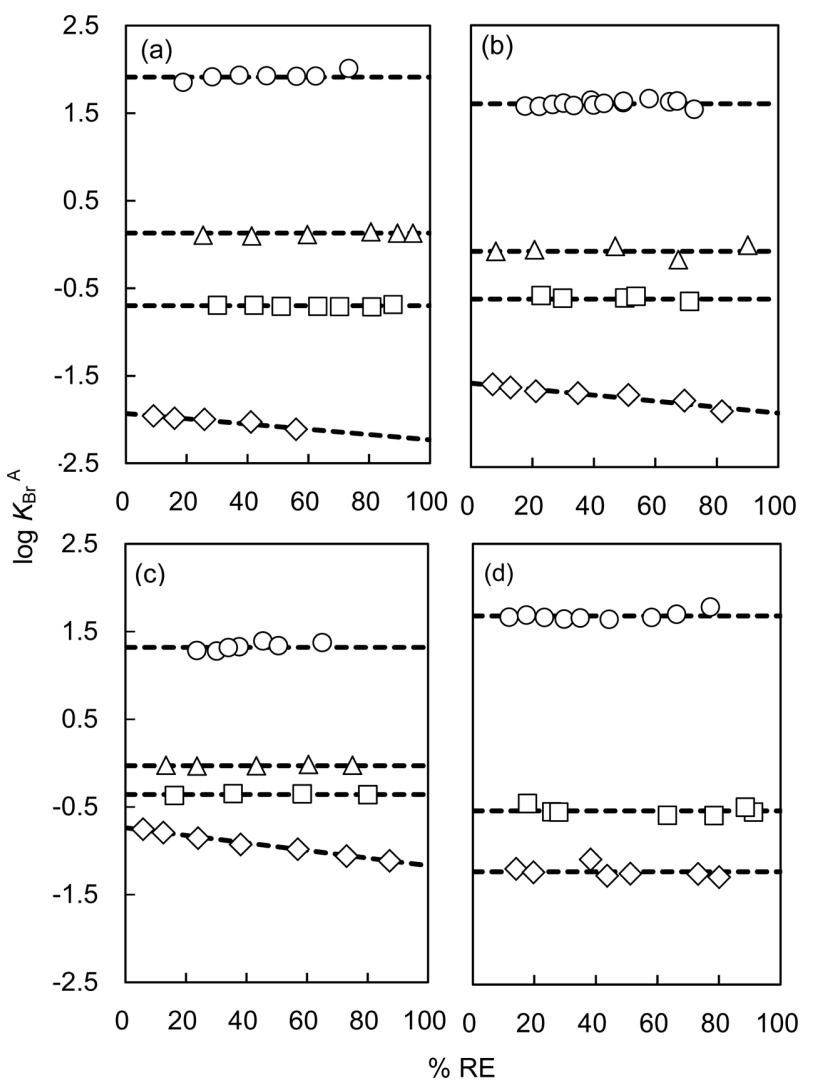

Fig. 2 RE dependency of $\log K_{\mathrm{Br}}{ }^{\mathrm{A}}$ for four resins. (a) I- $1 \times 2$ (b) $\mathrm{I}-3 \times 8$ (c) I-3 $\times 2$ (d) II- $2 \times 8 . \mathrm{A}^{-}: \bigcirc, \mathrm{ClO}_{4^{-}}^{-} ; \triangle, \mathrm{NO}_{3}^{-} ; \square, \mathrm{Cl}^{-} ; \diamond, \mathrm{F}^{-}$.

\section{Comparison of resins}

The selectivity coefficients of four anions on four SBAs and those of two or three anions on three WBAs are summarized in Table 2 and are compared in Fig. 3, where the values at $\mathrm{RE}=$ 0.5 are taken for $\log K_{\mathrm{Br}}^{\mathrm{F}}$ of $\mathrm{I}-1 \times 2, \mathrm{I}-3 \times 8$ and $\mathrm{I}-3 \times 2$. The difference between $\log K_{\mathrm{Br}}{ }^{\mathrm{ClO} 4}$ and $\log K_{\mathrm{Br}}{ }^{\mathrm{F}}$ of trimethylaminomethyl-type SBAs decreased in the order of $\mathrm{I}-1 \times 2(3.99)>$ $\mathrm{I}-3 \times 8(3.34)>\mathrm{I}-3 \times 2(2.29)$. The resin of $\mathrm{I}-1 \times 2$ contains an appreciable amount of styrene without an ammonium group and provides a more lipophilic or less hydrophilic environment. Thus, a lipophilic anion is more favorably exchanged, while a hydrophilic anion is more poorly exchanged. In contrast, I- $3 \times 2$ affords the more hydrophilic environment and loses the differentiating ability by as much as 1.7 in logarithmic scale. The resin of $\mathrm{I}-3 \times 8$ is less flexible than $\mathrm{I}-3 \times 2$ and shows the intermediate ability. The resin of II- $2 \times 8$ showed the higher selectivities to the anions of the hydrogen bond acceptor, such as fluoride and nitrate, compared with $\mathrm{I}-3 \times 8$. WBAs also showed the higher selectivities to the nitrate of the hydrogen bond acceptor; this trend was more remarkable for the resins of the lower nitrogen content as in the cases of SBAs.

\section{Conclusions}

Perchlorate is almost quantitatively exchanged when in contact with anion exchange resins. Under such conditions, $\left[\mathrm{ClO}_{4}^{-}\right]$ buffered at the low level in the supernatant was successfully determined by potentiometry with ISE to give a reasonable selectivity coefficient. This method is generally applicable to any lipophilic anions.

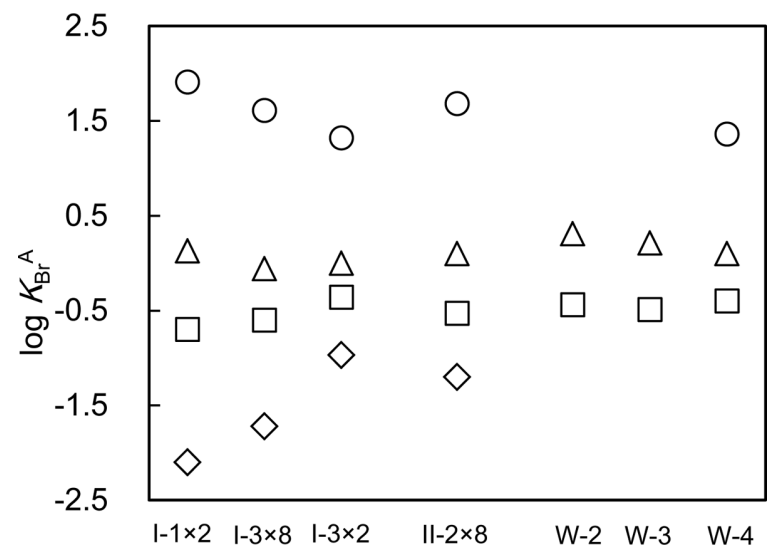

Fig. 3 Comparison of $\log K_{\mathrm{Br}}{ }^{\mathrm{A}}$ of four resins. $\mathrm{A}^{-}: \bigcirc, \mathrm{ClO}_{4}^{-} ; \triangle, \mathrm{NO}_{3}^{-}$; $\square, \mathrm{Cl}^{-} ; \diamond, \mathrm{F}^{-}$.

Table 2 Logarithmic values of selectivity coefficients $\left(K_{\mathrm{Br}}{ }^{\mathrm{A}}\right)$ of four anions on seven resins ${ }^{\mathrm{a}}$

\begin{tabular}{|c|c|c|c|c|}
\hline \multirow{2}{*}{ Resin } & \multicolumn{4}{|c|}{$\mathrm{A}^{-}$} \\
\hline & $\mathrm{ClO}_{4}^{-}$ & $\mathrm{NO}_{3}^{-}$ & $\mathrm{Cl}^{-}$ & $\mathrm{F}^{-}$ \\
\hline $\mathrm{I}-1 \times 2$ & $1.91 \pm 0.03(6)$ & $0.13 \pm 0.02(5)$ & $-0.70 \pm 0.00(6)$ & $-1.93-0.30 \times \mathrm{RE}(8)$ \\
\hline $\mathrm{I}-3 \times 8$ & $1.61 \pm 0.03(14)$ & $-0.1 \pm 0.1$ & $-0.60 \pm 0.05(7)$ & $-1.55-0.34 \times \operatorname{RE}(7)$ \\
\hline $\mathrm{I}-3 \times 2$ & $1.32 \pm 0.05(8)$ & $-0.03 \pm 0.03(6)$ & $-0.36 \pm 0.01$ & $-0.75-0.43 \times \mathrm{RE}(5)$ \\
\hline II $-2 \times 8$ & $1.68 \pm 0.04(9)$ & $0.02 \pm 0.02(7)$ & $-0.53 \pm 0.04(7)$ & $-1.2 \pm 0.1(7)$ \\
\hline $\mathrm{W}-2$ & n.d. ${ }^{b}$ & $0.31 \pm 0.03$ & $-0.44 \pm 0.05$ & n.e. ${ }^{c}$ \\
\hline W-3 & n.d. ${ }^{b}$ & $0.21 \pm 0.02(6)$ & $-0.49 \pm 0.02$ & n.e. ${ }^{\mathrm{c}}$ \\
\hline W-4 & $1.36 \pm 0.04(15)$ & $0.10 \pm 0.01(8)$ & $-0.40 \pm 0.04(6)$ & n.e. ${ }^{c}$ \\
\hline
\end{tabular}

a. Number of samples in parentheses. b. n.d.: not determinable. c. n.e.: not evaluated. 


\section{Acknowledgements}

This work was supported by the Japan Society for the Promotion of Science (JSPS) KAKENHI Grant Nos. 23550093 and 26410148.

\section{Supporting Information}

Additional tables showing the numerical data on ion exchange. This material is available free of charge on the Web at http:// www.jsac.or.jp/analsci/.

\section{References}

1. "Perchlorate in the Environment", ed. E. T. Urbansky, 2000, Kluwer/Plenum, New York.

2. B. Gu, "Perchlorate Environmental Occurrences, Interactions, and Treatment", ed. J. D. Coates, 2006, Springer, New York.

3. L. Ye, H. You, J. Yao, and H. Su, Desalination, 2012, $298,1$.

4. B. Gu, G. M. Brown, P. V. Bonnesen, L. Liang, B. A. Moyer, R. Ober, and S. D. Alexandratos, Environ. Sci. Technol., 2000, 34, 1075.

5. B. Gu, G. M. Brown, J. Maya, M. J. Lance, and B. A. Moyer, Environ. Sci. Technol., 2001, 35, 3362.

6. B. Gu, Y.-J. Ku, and G. M. Brown, Environ. Sci. Technol., 2005, 39, 901.

7. B. Gu, G. M. Brown, and C.-C. Chiang, Environ. Sci. Technol., 2007, 41, 6277.

8. Z. Xiong, D. Zhao, and W. F. Harper Jr., Ind. Eng. Chem. Res., 2007, 46, 9213.
9. D. P. Chen, C. Yu, C.-Y. Chang, Y. Wan, J. M. J. Frecht, W. A. Goddard, and M. S. Diallo, Environ. Sci. Technol., 2012, 46, 10718.

10. R. M. Wheaton and W. C. Bauman, Ind. Eng. Chem., 1951, 43, 1088 .

11. H. P. Gregor, J. Belle, and R. A. Marcus, J. Am. Chem. Soc., 1955, 77, 2713.

12. J. Aveston, D. A. Everest, and R. A. Wells, J. Chem. Soc., 1958, 231.

13. S. Lindenbaum, G. E. Boyd, and G. E. Myers, J. Phys. Chem., 1958, 62, 995.

14. D. H. Freeman, J. Chem. Phys., 1961, 35, 189.

15. I. Eliezer and Y. Marcus, J. Inorg. Nucl. Chem., 1963, 25, 1465.

16. J. Inczédy, J. Chromatogr., 1974, 102, 41.

17. A. Marton, Pure Appl. Chem., 1997, 69, 1481.

18. A. R. Tripp and D. A. Clifford, "Ion Exchange and Solvent Extraction", ed. A. K Sengupta and Y. Marcus, 2004, Vol. 16, Marcel Dekker, New York.

19. B. A. Moyer and P. V. Bonnesen, "Supramolecular Chemistry of Anions", ed. A. Bianchi, K. Bowman-James, and E. Garcia-Espana, 1997, Wiley-VCH.

20. M. Xu, Z. Ou, Z. Shi, M. Xu, H. Li, S. Yu, and B. He, React. Funct. Polym., 2001, 48, 85.

21. A. Yuchi, S. Kuroda, M. Takagi, Y. Watanabe, and S. Nakao, Anal. Chem., 2011, 82, 8611.

22. J. S. Früchtel, and G. Jung, Angew. Chem., Int. Ed. Engl., 1996, 35, 17.

23. K. Hartman, S. Luterotti, H. F. Osswald, M. Oehme, P. C. Meier, D. Ammann, and W. Simon, Microchim. Acta, 1978, 70, 235.

24. A. Inui, C. Hama, T. Katsuragawa, S. Iwata, and A. Yuchi, Ind. Eng. Chem. Res., 2013, 52, 16880. 